\title{
Research Types in Science Education Journal Articles: Identifying Major Trends
}

\author{
Konstantinos Karampelas ${ }^{1 *}$ (1)
}

${ }^{1}$ Department of Elementary Education, School of Humanities, University of the Aegean, Rhodes, GREECE

*Corresponding Author: kkarampelas@aegean.gr

Citation: Karampelas, K. (2022). Research Types in Science Education Journal Articles: Identifying Major Trends. Contemporary Mathematics and Science Education, 3(1), ep22006. https://doi.org/10.30935/conmaths/11815

\begin{abstract}
This study aims to identify the research types that authors of science education journal articles tend to select for their studies. It focused on articles published during the last decade. Selection of the appropriate research type is a significant process in education research. Depending on factors such as the goals that the researchers set or the conditions within which they work, they may select the implementation of quantitative studies, such as experimental study, field survey, secondary data analysis, and case research. They may select the implementation of qualitative studies such as case study, focus group, action research, and ethnography. Finally, they may select the implementation of mixed study. Therefore, by researching the types of research in published articles it is possible to gain insights about what goals the researchers set and their work context. This was the objective of this research. 2,071 articles in refereed journals in science education were collected. These articles were published between 2011-2020. The methodology included descriptive statistics and distribution calculation through a Kolmogorov Smirnov test. The findings showed that there is a preference to the qualitative type, even though there is a considerable number of studies to other types as well.
\end{abstract}

Keywords: research types, research trends, science teaching, journal articles

Received: 23 Dec. $2021 \bullet$ Accepted: 21 Feb. 2022

\section{INTRODUCTION}

The scope of this paper is to clarify what research types are identified in journal articles that address the field of science education. Journal articles are a significant part of research and research dissemination. By researching them it is possible to identify the topics, attitudes, and trends that dominate a certain field of study, such as education or science education, specifically. Journal articles represent a study or a part of a study that is expected to contribute to the field. In doing so, the study needs to adopt an appropriate paradigm, such as qualitative or quantitative and an appropriate type, such as experimental studies, field surveys, secondary data analysis, case research case studies, focus groups, action research, and ethnography (Bhattacherjee, 2012; Cohen et al., 2011; Pring, 2000; Tobin \& Steinberg 2015).

The selection of the appropriate paradigm and type depends on many factors. The researchers and authors decide what type suits their research, bearing in mind different factors, such as the nature or scope of their research as well as the conditions of their work and the means they have access to. Therefore, by researching the types observed in journal articles, it is possible to give insights these factors that influence the scope of the researcher's work' (Bhattacherjee, 2012; Pring, 2000).
The paper aims to achieve the aforementioned main goal through the bibliometrics approach. In order to achieve this, it is important to highlight the main theoretical points around education research, its types and paradigms, along with the main theoretical points around the specific field of study-science education. (Lin et al, 2019; Tobin \& Steinberg 2015).

\section{Bibliometrics in Education}

According to Donthu et al. (2021), the field of bibliometrics has been gaining popularity over the last decades for various reasons. It addresses data collection from resources such as books and journal articles. Thanks to the access to such resources, a wealth of information, findings, and literature regarding a certain area can be gathered, as well as the development of appropriate methods and practices to manage this whenever required. Bibliometrics assist in observing and viewing the progress of research and pointing out trends in a field such as education or to be even more specific, science education. Researchers can analyze a large number of articles in bibliometrics and therefore, it is justifiable that bibliographical research is highly accurate. Moreover, researchers can get an idea of the cumulative approach to a field', find out gaps in research, develop ideas, and contribute appropriately to progress and development.

There are different ways in which bibliometric research is carried out, which can be adopted by groups of theorists or researchers, based 
on what fits their particular project the best. In other words, it has not been possible to determine the existence of an authoritative and universally accepted pattern of carrying out the bibliometric research and methodology so far. This is largely because bibliometric analysis attracted growing interest only recently. However, planning a bibliometric analysis can be done from existing literature (Donthu et al., 2021; Salini, 2016).

Among the various modes of bibliometric research, the one that fits this research aptly is to identify patterns and dynamics within a specific research field (Cobo et al., 2011; Zupic \& Čater, 2014). Even more specifically, this mode of research is an example of a 'co-word' (Callon et al., 1983) bibliometric analysis, which aims to investigate the content of the articles studied. Such a study aims to identify common concepts that exist in multiple articles and reflect hidden themes and relationships. Zupic and Čater (2014) suggest a five-step approach to carrying out such a study. First, there is the research design, where the main theme and the appropriate research question is identified, formed, and stated clearly. Second, there is the data collection process, which is the compiling of bibliometric data. This requires selection of the resources, the database, and the filtering of information and mass data that are gathered. Third, there is the analysis. This involves using an appropriate software, importing the data in it, and identifying some initial patterns and maybe subgroups. Further filtering of data can be done at that stage if necessary. Fourth, there is the visualization and representation. the visualization and representation of the data and patterns found to have disseminated in a particular way is the fourth stage. Finally, there is the interpretation of data and the justification of their rational and main points.

The scope of this study is to identify trends and dynamics in education research and the field of science teaching. Therefore, it is necessary to go through the main theoretical points and research findings around these themes (Cohen et al., 2011; Pring, 2000).

\section{Education Research}

\section{The scope of education research}

Education research is expected to contribute new information to the field of education science. This contribution is considered accurate only when research follows an accepted methodological approach. Researchers need to be careful when planning their study and ensure that they follow the appropriate methodology. Depending on the selected methodological approach, a research study can be classified into different categories. The first and perhaps the most basic categorization of educational and social research includes two approaches-the positivist approach and the non-positivist approach, also known in some research theories as the interpretive approach (Cohen et al., 2011; Tobin \& Steinberg, 2015; Walliman, 2011).

The positivist approach is considered as the appropriate type of scientific research. Researchers who adopt this approach usually form a hypothesis, based on the theories and literature they have analyzed and aim to test its validity. In doing so, they use numerical data. In other words, it follows a quantitative approach. Moreover, they analyze them with the help of statistics. By evaluating the hypothesis, the researchers seek a generalization, which may lead to the formulation and dissemination of a new theory. This means that through the empirical selection of data, they adopt a rather deductive approach, which will help with the development of the desired theory. The positivist approach is generally associated with laboratory experiments, which aim to prove or present a new scientific finding that can be generalized and have universal value or application. Therefore, it is associated to an inductive approach to learning and contribution to knowledge (Cohen et al., 2011; Szyjka, 2012).

The non-positivist approach is aimed at deriving a theory that focuses on a specific topic with the help of relevant data. Its main focus is more oriented to test a particular theory, concept, or pattern using new data. Testing a theory with different sets of data and different concepts can lead to the refinement, improvement, and broadening of an accepted theory. Data have to be gathered and analyzed in depth and thoroughly in this case as well. Usually, the data for this type of research might be obtained through tools and techniques such as interviews, documents, diaries, biographies, or observations, which are commonly considered as qualitative data. Overall, this research paradigm is associated with the deductive approach to learning and contribution to knowledge.

In practice, there are groups of researchers claiming that it is not justified to totally link the positivistic approach to the quantitative method, and similarly, the non-positivistic approach to the qualitative one. Certainly, it is common to note positivist research focusing on regression and statistics and therefore on quantitative data. However, it is also possible to use qualitative data in this research. Non-positivist research frequently relies on coding and therefore on qualitative data, but it may also use quantitative data. In fact, it is becoming more and more common for researchers to employ a mixed paradigm. This helps achieve a more complete approach to studying a complex phenomenon, thereby giving a more reliable and accurate point of view (Bhattacherjee, 2012; Pring, 2000; Walliman, 2011).

\section{Research types}

Both the qualitative and quantitative paradigm cover a broad range of research fields. Therefore, each of them includes different categories of projects depending on the design, content, scope, and structure. The positivist paradigm entails categories such as experimental studies, field surveys, secondary data analysis, and case research. The non-positivist paradigm might involve categories such as case studies, focus groups, action research, and ethnography (Bhattacherjee, 2012; Pring, 2000).

Experimental studies are usually related to projects that test a causeand-effect relationship. Generally, such tests examine the influence of a factor in a specific group, called the treatment group. This is benchmarked against the performance of another one, known as the common group, wherein the studied factor does not exist. Due to this comparison, it is possible to point out how this factor influences performances generally. For instance, an experimental study in medicine might include administering therapy to a specific group of patients. By comparing their progress with that of other patients who did not receive it, it is possible to infer its effectiveness. In education, an experimental study might include teaching a subject through an innovative method and comparing the performance of students with those who are taught with mainstream methods. Such studies usually rely on quantitative analysis. They are considered valid as they can isolate, control, and carefully examine the variable. On the other hand, caution should be exercised when their findings are subjected to generalization as other factors and variables have to be taken into consideration (Bhattacherjee, 2012; Cohen et al., 2011; Pring, 2000).

Field surveys focus on the effects of specific variables as well. These variables might pertain to topics such as beliefs, ideas, problem 
frequencies, or other general conditions. They do not draw comparisons as experimental studies do. Using statistical methods, they measure the extent to which these variables may influence certain samples and population. The most common data collection tool in a survey is the questionnaire. The variables might be tested within a specific timeframe, for example, in longer time periods, when the research is of longitudinal status. The main advantage of field surveys is that they collect data from actual, realistic field settings. However, the data may be subject to bias.

Secondary data analysis refers to the type of research that analyzes existing data, collected by groups-governmental organizations, authorities, or institutes. Such information might be publicly available. In this case, data collection task is facilitated through researchers, who are usually in charge of the same. The main advantage of this type of research is that it assists in cases where data collection might demand cost and time. However, researchers should be careful when using these data since they probably have been collected for purposes that differ from the ones of the research. This point calls for attention when addressing the research question and justifying the methodology. The risk of drawing invalid conclusions and findings is dealt with this way (Bhattacherjee, 2012; Cohen et al., 2011; Pring, 2000).

A case study focuses on a particular problem or phenomenon, as it emerges in a specific context, over a defined period of time. The required data might be derived from different resources or tools such as interviews, observations, or documents. A case study might be of both a positivistic and interpretive nature. Because of this flexibility, it has significant advantages. The most important one is that it can be conducted in a variety of situations to examine different types of phenomena-social, cultural, and political. However, there are some disadvantages to using case studies. The analysis is heavily contextualized and dependent on the researchers' personality, attitudes, bias, and beliefs. Since it examines an individual case, it is not always possible to generalize its findings. However, through multiple case studies of the same phenomenon or context, generalizations might be possible.

Focus groups are commonly used in exploratory research. They can provide a holistic approach to a problem or phenomenon by collecting and analyzing opinions and ideas from a small group of people. These are the participants, who are gathered and involved in a discussion guided by the researchers. Within a focus group, the participants provide data by answering questions asked by the researchers according to a set agenda. One the one hand, the holistic approach that they provide can be a significant advantage. On the other hand, as with the case study, there are concerns about the possibility to generalize the findings, from studies utilizing focus groups. The reason behind is that it focuses on a certain context. Nonetheless, they are very helpful in elaborating a certain phenomenon (Bhattacherjee, 2012; Cohen et al. 2011; Pring, 2000).

Action research centers on the idea that a phenomenon or topic can be understood and investigated better through sets of designed interventions or actions undertaken by the researchers themselves. In that case, the researchers are members of a group, an organization, or a context that they seek to investigate or improve. They appropriately intervene to implement activities that can lead to problem solving or the desired improvement. For example, they may be teachers who are trying out new technological applications in their classes, aspiring to achieve better teaching outcomes for their school or organization. To this end, the researchers collect the data and analyze them as planned. Findings are then drawn based on a certain theory about the context or topic studied. By using action research, it is possible to get insights on unique phenomena in their specific contexts. However, this might restrict the potential of the findings to be generalized (Bhattacherjee, 2012; Cohen et al., 2011; Pring, 2000; Walliman, 2011).

Ethnography is a type of interpretive research that is adopted by the field of anthropology. In this type, researchers engage with an organization, a community, or context, and they study its functions, behaviors, actions, and aspects, usually for longer periods that might last for months or even years. Ethnographic data are collected through observations or interviews. Researchers must, however, make sure they do not influence participants with their presence and stay 'invisible' to the maximum possible levels. The main advantage of ethnography is that it helps particular and perhaps unknown contexts to be studied, familiarized, and understood. As with the previous types, there is although questions regarding the generalizability of its outcomes (Bhattacherjee, 2012; Cohen et al., 2011; Pring, 2000).

\section{Selecting the design}

Any group of researchers who are willing to undertake a study should pay attention while determining which design best fits their goals. The design should be treated as a foundation for the planning of the research. All stages of the study should be compatible with the characteristics of the selected design. Hence, the design also assists the researchers in precising the sub-tasks and the development of the research plan. By having the focus and strengths of the design in mind, the researchers can be more certain about what and how they were doing in every step of their work

Overall, the principal criterion that the researchers will consider selecting the appropriate design is the research question. It entails the essence and aim of the study, as well as its rationale. It is not prudent to have the idea that the research question can be answered by any type of response. Thus, researchers need to identify a specific design. It is the only way by which they can get valid, credible, acceptable, and generalizable outcomes that will either formulate or enhance a theory. Using different designs might disorientate the work of researchers, the data collection, or analysis and provide differentiated or irrelevant findings. In short, the selection of the design should be based on the nature of the research question and the phenomenon under study. At least, this should be the ideal selection process (Bhattacherjee, 2012; Pring, 2000; Walliman, 2011).

From a realistic point of view, researchers might also consider other relevant factors such as their own personality, interests, and the general work conditions. It is not very rare for researchers to be uncertain about the research question and the exact focus of their work at the preliminary stages of their research. In that case, researchers might opt for a focus group or case study and carry out exploratory research. Since these types depend on individual aspects or parts of a system, the researchers have the appropriate conditions to give insights into it.

As soon as researchers understand and identify the theory or set of theories that relate to the topic they are investigating, they may choose positivist research that involves experiments, field surveys, or secondary data analysis. In doing so, they take advantage of data resources and samples they have access to. Usually, a considerably large number of participants are needed in these types of research. This way 
they may achieve $d$ the development a greater, updated theory (Bhattacherjee, 2012; Pring, 2000).

However, if the researchers realize that there is no directly apparent theory to explain the phenomena they are working on, they may opt for action research or ethnography and employ an interpretive design. These types of research provide researchers with the opportunity to treat the investigated system as a totality. They also have the flexibility to use existing theories indirectly linked to the topic and evaluate whether they can be implemented in the studied context. Consequently, the researchers in this case may perhaps provide innovative explanations of already explained phenomena (Bhattacherjee, 2012; Pring, 2000).

In short, the selection of the types that researchers believe their work fits it depends on certain factors such as their goals and the context where they work (Bhattacherjee, 2012; Cohen et al., 2011). With the help of bibliometrics, by identifying the trends and dynamics around these topics, it is possible to gain insights on the factors that influence the researchers (Donthu et al., 2021).

\section{Science Teaching}

\section{Scientific literacy}

The primary goal of science education is the development of scientific literacy. Several groups of researchers aimed to provide a wellstructured and clear definition for the term. A definition of scientific literacy was given by the Organization of Economic, Cooperation, and Development [OECD] (2000):

"The capacity to use scientific knowledge, to identify questions, and to draw evidence-based conclusions in order to understand and help make decisions about the natural world and the changes made to it through human activity" (p. 10).

By virtue of various reasons, such as the developments in science, technology, and social studies-including education-the approach to scientific literacy stays updated. For example, new ideas and attitudes concerning what the goals of education are arise, generally and specifically in areas such as science teaching. Besides, there are shifts in the topics that concern science experts and therefore in the topics that are considered worth teaching too.

Scientific literacy, as currently perceived, involves three basic dimensions. The first is the learners' ability to describe and explain scientific phenomena. The second is the capability to plan, conduct, and evaluate scientific inquiries and tasks. Finally, the third is the ability to interpret data and evidence. All these abilities are interrelated. They correspond to the general principles that learners should participate actively in teaching sessions and activities and that teaching should be planned based on the learners' experience. These principles are highly promoted as foundational for contemporary teaching practices as they are considered to lead to effective teaching (Botes, 2021; Kazempour et al., 2020; McCollough et al., 2019; NGSS, 2012; OECD, 2000; Viro et al., 2020).

More specifically, the first ability has to do with knowledge. This knowledge refers to processed, analyzed, and generalized data that is relevant to issues of science and technology. This might be connected to the capacity of a person to define concepts, describe phenomena, and explain processes. It might also be related to their capacity to link knowledge with everyday life experiences. This means linking the data observed in everyday life to the concepts or phenomena that are scientifically proven.

The second ability pertains to how this knowledge is approached and processed. In other words, it has to do with the understanding of methodology and tasks, by which the data and observations from everyday life can lead to the desired scientific knowledge. Through understanding, it is possible to appreciate and justify the validity of knowledge, generally and specifically. It can also prevent the possibility of accepting any kind of knowledge that is not derived through proper methodological approach that can be false (Botes, 2021; McCollough et al., 2019; NGSS, 2012; OECD, 2000).

Lastly, the third ability deals with developing the capacity to implement scientific methodology to acquire knowledge, either already known or maybe even new or updated. By applying the appropriate methodology, data and evidence can be interpreted. These can then be converted to concepts or phenomena, which can be further employed to interpret new data and evidence. Certainly, the barriers between these abilities are not precise and clear. Achieving scientific literacy requires the acquiring and combining of all three (Botes, 2021; McCollough et al., 2019; NGSS, 2012).

Researchers interested in the field of science teaching focus on identifying ways through which scientific literacy can be achieved. The topics they may emphasize can be various-teaching practices that educators can use in classroom; curricula and other teaching material; school conditions and their impact on teaching and learning; social and cultural aspects such as gender and family background factors; teaching tools such as textbooks and information and communication technologies (ICT); teacher training and professional development; and foundational aspects of science such as history, philosophy, and the nature of science. These are the basic topics that researchers have paid attention to and emphasized (Chang et al., 2009).

\section{Justification of the study}

The purpose of the study is to point out what types of research, experts in the field of science teaching tend to select for their research projects. Bibliometrics is an appropriate approach for this study, since it can give the opportunity to identify trends in research types selected from published articles in refereed journals (Cobo et al., 2011; Donthu et al., 2021; Zupic \& Čater, 2014).

As mentioned, for a research study to be effective, it is important for researchers to select the appropriate design. This selection will be influenced by different factors. In science teaching, as it happens generally in research, the basic criteria will be the research question and scope, the conditions and context of the study, the resources available, and the personality of the people involved. Having in mind the broad classification of the positivist paradigm, which includes experimental studies, field surveys, secondary data analysis, case research, and the interpretive paradigm including case studies, focus groups, action research, and ethnography, it is important to apply it to the context of science teaching and the relevant research. It is therefore important to see how this classification can get or be adapted when examining the points that researchers in science education focus on. This can result in a specialized classification (Lin et al., 2019).

Limited seem to be the studies to identify trends in science education research types selection of recent publications. There has been a number of projects examining research trends in science education, during the previous decades. Various researchers such as 
Cavas et al. (2012), De Jong (2007), Szyjka (2012), Tsai and Wen (2015), and White (1997) have identified the trends in research paradigms that dominated science teaching from 1970-2010. The main conclusion is that there has been a surge in qualitative research. They attribute these trends to various reasons. It could be that researchers started realizing that there is a risk in attempting the generalization of findings derived from large populations that might not be similar or representative. In relation to that, he believes that there has been a shift in the interest to identify direct classroom experience. In other words, researchers preferred to get in the classroom and directly research the reality of the teachers and learners as well as the education system. They are focused on instruction, curriculum implementation, teaching practices, and methods. Hence, researchers probably select the qualitative method to verify theories and findings in different actual school or classroom contexts. Certainly, quantitative research and mixed methods are still used by science education specialists and researchers. The quantitative method is still preferred for research at national or international levels. Such projects are carried out by national and international agencies that have the means and connections to access the data and large population required for quantitative research. Usually, governments tend to utilize such projects to evaluate educational reforms and conditions. This research attempts to precise these trends using bibliometric approaches (Cobo et al., 2011; Donthu et al., 2021; Zupic \& Čater, 2014).

\section{METHODOLOGY}

The basic points around bibliography, education research, and science education were the central focus of the study. The selection of the research type is a very important decision for researchers. It is associated with their goals and interests, as well as the conditions under which they do their studies and work. Therefore, it is possible to draw significant conclusions by analyzing they types they select from the journal articles published. These can be of quantitative nature, such as experimental studies, field surveys, secondary data analysis, and case research. They can also be of qualitative nature, such as case studies, focus groups, action research, and ethnography. They can also be mixed (Bhattacherjee, 2012; Cohen et al., 2011; Pring, 2000; Walliman, 2011). Certain relevant studies have been done in the field of science education. Findings of them show that from 1970 until 2010 researchers tend to select the qualitative types. Probably this has to do with their preference to focus on rather small samples and examine whether certain theories apply practically in certain contexts (Cavas et al., 2012; Chang et al., 2009; De Jong, 2007; Lin et al., 2019; Szyjka, 2012; Tsai \& Wen, 2015; White, 1997).

The study tries to identify trends in published journal articles. It was designed according to the five-step approach of Zupic and Čater (2014) of bibliometric research. The first step is to identify the main question which has do to with what types researchers in the field of science education select for their projects. More specifically, the research questions are framed as follows:

1. What types of research have been preferred by researchers over the last decade?

2. Is there an equal distribution among the types of research?

3. Are there new trends compared with those of previous decades?

The second step is the data collection. The data from this research came from articles published in journals specializing in science education. These articles were published between 2011-2020, since there is shortage in studies that have examined the research trends in science teaching during that period of study. Searching was done with the help of the search engine of the journal's website and more specifically thanks to the function of advanced search. The search was limited to articles from January 2011-December 2020. The search was accustomed to the concepts of the research types. Accordingly, the terms 'quantitative', 'interpretive', or 'positivistic' were used to collect the articles publishing quantitative research studies. Afterwards, there were a series of further searches within these articles to determine the exact type of quantitative study. Initially the concept 'experimental study' was typed, then, 'field survey', 'secondary data analysis, and 'case research' to collect the articles that published the relevant research types.

Similar was the process used for the quantitative journals. Initially there was search with the concepts 'quantitative', 'non-positivist' or 'descriptive'. Afterwards, further attempts of search were done within these articles with the concepts 'case study', 'focus groups', 'action research' and 'ethnography'. Finally, there was search done with the concept 'mixed' or 'quantitative AND qualitative' to collect articles that carried mixed research. Certainly, bearing in mind that some terms can be used for many contexts, not only for methodology, further reading and checking of these articles was necessary. This was the case especially with the word 'mixed'. This is one reason why it was not easy at that stage for large number of journals, issues to be collected and analyzed. This is a common limitation arising in the case of 'co-word' bibliometrics research. The selection of these types is common in modern bibliometric analysis studies (Donthu et al., 2021; Zupic \& Čater 2014).

The third step is the analysis. This research is of quantitative nature, as is common for bibliometric studies, which examine large samples or articles (Donthu et al., 2021). It focuses on identifying trends. It is therefore necessary to identify the variables that can reflect or quantify trends. These values are the ones used in descriptive or inferential statistics. Firstly, the absolute and relative frequencies were calculated. This gave the results to the first research question. Secondly, the distribution was studied. To this end, the Kolmogorov-Smirnov test was performed. More specifically, this was a one-pair test, calculated with the help of the Statistical Package for Social Sciences, SPSS (Walliman, 2011). This gave answers to the second research question. Lastly, the main findings were benchmarked against the ones discussed in previous research projects or theories. This provided the answer to the third research question (Bhattacherjee, 2012; Cohen et al., 2011; Pring, 2000). Previous studies have implemented similar quantitative methodologies. Thanks to the use of bibliometrics, this study aims to develop a new approach. By identifying these trends, and answering the research questions, the dynamics of research in the science education field aim to be described (Cobo et al., 2011; Zupic \& Čater, 2014).

The fourth step involved the visualization and representation process. A total of 2,071 articles were gathered. All these were classified depending on the type of research selected. At first, it was noted whether the research was quantitative, qualitative, or mixed. The results and values, as calculated with the help of SPSS will be first presented in tables. They were analyzed by being benchmarked with the relevant bibliography. It was important at this stage to clarify codes and the contained nodes, relevant to the topic and the study. This was based on composing the diagram of these nodes to illustrate trends. The nodes 
Table 1. Absolute and relevant frequencies for each paradigm and type

\begin{tabular}{lcc}
\hline Research type & Absolute frequency & Relevant frequency (\%) \\
\hline Quantitative & 867 & 41.86 \\
\hline Experimental studies & 334 & 16.13 \\
\hline Field surveys & 345 & 16.66 \\
\hline Secondary data analysis & 156 & 7.53 \\
\hline Case research & 32 & 1.55 \\
\hline Qualitative & 1,158 & 55.92 \\
\hline Case studies & 501 & 24.19 \\
\hline Focus groups & 563 & 27.18 \\
\hline Action research & 29 & 1.40 \\
\hline Ethnography & 65 & 3.14 \\
\hline Mixed & 46 & 2.22 \\
\hline Total & $\mathbf{2 , 0 7 1}$ & $\mathbf{1 0 0 . 0 0 \%}$ \\
\hline
\end{tabular}

of the study coincide with the research types. One code can be 'quantitative', which includes the nodes 'experimental studies', 'field surveys', 'secondary data analysis' and 'case research'. Another code is 'qualitative', which includes the nodes 'case studies', 'focus groups', 'action research', 'ethnography'. Finally, the third code is 'mixed'. This process can rely on the use of appropriate software (Donthu et al., 2021; Zupic \& Čater, 2014). A software suitable for this case is SPSS (Walliman, 2011).

The final step is the justification and interpretation of the results. (Donthu et al., 2021; Zupic \& Čater, 2014;). In this study, the main question is whether the trends observed in previous decades in science education articles are still observed. During that period, there was a preference on behalf of the researchers in qualitative studies instead of quantitative or mixed (Cavas et al., 2012; Chang et al., 2009; De Jong, 2007; Lin et al., 2019; Szyjka, 2012; Tsai \& Wen, 2015; White, 1997). Certainly, over the last decade there have been several social changes that can have influenced the interests and goals of researchers and educators with regards to the field of science teaching. This shift can be relevant to topics and areas of interest. An example of this shift might be the development of the eight practices of science teaching (NGSS, 2012). Nevertheless, there has been little development to issues that might concern the researchers' selection of research types. The new approaches and practices that have been introduced in the field of science teaching might be tempting the researchers to investigate their implementation. In other words, researchers might want to focus their work in testing the new approaches in actual classroom settings and different educational contexts. In doing so, however, they will probably use qualitative research rather than the other paradigms. Under these circumstances there is limited possibility for new trends in selecting research types to arise (Bhattacherjee, 2012; Cohen et al., 2011; Pring, 2000).

\section{FINDINGS}

As shown in Table 1, where the absolute and relevant frequencies are displayed, the majority of the articles studied were of qualitative nature. This accounts for $55 \%$, which is more than half of the studied journal articles. Among them, the most frequent types of research were case studies as well as focus groups. In fact, the articles associated with these two types alone slightly surpasses $50 \%$ of the total as out of the 2,071 articles, the number of those belonging to each of these types exceeded 500. This was not the case in any other type. The frequency of the other two types-action research and ethnography-was
Table 2. Statistic values

\begin{tabular}{|c|c|c|}
\hline \multicolumn{3}{|l|}{ VAR00001 } \\
\hline \multirow{2}{*}{$\mathbf{N}$} & Valid & 9 \\
\hline & Missing & 0 \\
\hline \multicolumn{2}{|l|}{ Mean } & 230.1111 \\
\hline \multicolumn{2}{|c|}{ Standard error of mean } & 70.17170 \\
\hline \multicolumn{2}{|l|}{ Median } & 156.0000 \\
\hline \multicolumn{2}{|l|}{ Mode } & $29.00^{\mathrm{a}}$ \\
\hline \multicolumn{2}{|c|}{ Standard deviation } & 210.51511 \\
\hline \multicolumn{2}{|l|}{ Variance } & $44,316.611$ \\
\hline \multicolumn{2}{|l|}{ Skewness } & 0.557 \\
\hline \multicolumn{2}{|c|}{ Standard error of skewness } & 0.717 \\
\hline \multicolumn{2}{|l|}{ Kurtosis } & -1.427 \\
\hline \multicolumn{2}{|c|}{ Standard error of Kurtosis } & 1.400 \\
\hline \multicolumn{2}{|l|}{ Range } & 534.00 \\
\hline \multicolumn{2}{|l|}{ Sum } & $2,071.00$ \\
\hline \multirow{3}{*}{ Percentiles } & $\underline{25}$ & 39.0000 \\
\hline & 50 & 156.0000 \\
\hline & 75 & 423.0000 \\
\hline
\end{tabular}

Note. ${ }^{\mathrm{a}}$ Multiple modes exist. The smallest value is shown

comparatively much smaller. Even though articles using quantitative research were not dominant, they were by no means few, since they comprised $42 \%$ of the papers studied. Among them, the most frequent types were experimental studies and field surveys. There were fewer articles that employed secondary data analysis and much fewer that used case research. Finally, there was a rather limited number of journal articles that adopted mixed methodology.

In short, all types of research have certainly been identified in the articles of the study. No type seemed to be missing. There were however differences noticed in the absolute and relevant frequencies. More specifically, most of the articles used qualitative research instead of quantitative or mixed methods. Among those, the most opted for case studies or focus groups. These are the trends shown directly from the absolute and relevant frequencies as answers to the first research question (Cohen et al., 2007; Walliman, 2011).

The fact that researchers seem to opt for the qualitative paradigm more might be attributed to their general goals. A reason might be that they are more interested in examining already established research findings in different contexts, reinforcing their accuracy this way. Their goals might be oriented more toward a deductive approach, whereby they are aiming to treat the context of their research holistically as a totality. Such research projects might focus on topics such as instruction, curriculum implementation, and research practices. Another explanation might be relevant to the general interests and conditions of their work. This means that researchers can have easier access to resources, participants, data, and contexts, where qualitative research can be implemented, so that they can provide a desired innovative or alternative aspect of an already established theory or research finding. However, the fact that there is a smaller but considerable number of quantitative studies shows that there are researchers who are more oriented toward a positivistic approach. They are interested in gathering data and doing statistical analysis to construct and come up with new scientific findings, which can be generalized and implemented (Bhattacherjee, 2012; Cohen et al., 2007; Pring, 2000; Szyjka, 2012). Table 2 depicts statistics values of the studies. Table 3 shows one-sample Kolmogorov-Smirnov test. 
Table 3. One-sample Kolmogorov-Smirnov test

\begin{tabular}{lcc}
\hline VAR00001 & & \\
\hline $\mathbf{N}$ & & 9 \\
\hline Normal parameters ${ }^{\mathrm{a}, \mathrm{b}}$ & Mean & 230.1111 \\
\cline { 2 - 3 } & Standard deviation & 210.51511 \\
\cline { 2 - 3 } Most extreme differences & Absolute & 0.228 \\
\cline { 2 - 3 } & Positive & 0.228 \\
\hline Test statistic & Negative & -0.170 \\
\hline Asymptotic Sig. (2-tailed) & & 0.228 \\
\hline Note. ${ }^{\text {a }}$ Test distribution is normal; ${ }^{\mathrm{b}}$ Calculated from data; ${ }^{\mathrm{c}}$ Lilliefors significance \\
correction
\end{tabular}

The fact that researchers seem to opt more for qualitative paradigm might be attributed to their general goals. A reason for that might be that they are more interested in examining already established research findings in different contexts, reinforcing their accuracy. Their goals might be oriented more towards a deductive approach, where they are aiming to treat the context of their research holistically as a totality. Such research projects might focus on topics such as instruction, curriculum implementation, and research practices. Another explanation might be relevant to the general interests and conditions of their work. This means that researchers can have easier access to resources, participants, data and contexts, where qualitative research can be implemented, so that they can provide a desired innovative or alternative aspect of the already established theory or research finding.

As it can be concluded from the tables, the distribution among the research types is statistically classified as normal. This is shown through the mean, the test value, which is higher than 0.05 , the value of kurtosis and skewness, as well as the ration between the values of types and the standard deviation. This shows, as explained that indeed there are some types that are preferred by the researchers, while there is a normally distributed trend towards others that are less frequently selected (Figure 1). The preferred ones are certainly case studies and focus groups, while ethnography, case research, action research, and mixed methods are not so much preferred (Walliman, 2011).

\section{DISCUSSION}

These data actually mean that there is no equal preference among the types. Simultaneously, it cannot be stated that there is a single one that is most popular whereas there is a specific that is constantly being rejected. This demonstrates that each type has significance and can be used by the researchers. Nevertheless, the context and the goals of researchers lead them to select certain types over others. This might be attributed to existing research trends that are emphasized in topics such as practices and evaluation of teaching strategies as implemented in the classroom. It might also be attributed to access those researchers and theorist have to certain types of data. For example, the fact that there are few examples of action research and ethnography might mean that it is not easy to get in a classroom for research purposes. It might also mean that teachers do not opt frequently to engage in researching their own classroom or work for reasons of ethical or legal nature, or maybe due to heavy workload (Cohen et al., 2007; Pring, 2000; Walliman, 2011).

Overall, these tendencies are compatible to the ones identified by previous research projects, which show a preference to the qualitative research. However, they do not explicitly state that quantitative

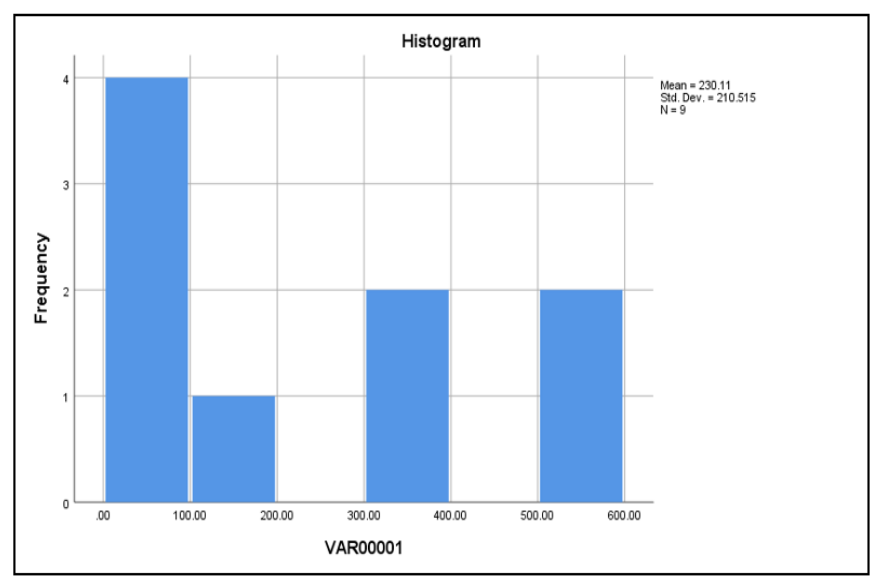

Figure 1. Distributions of trends

research is under the threat of extinction (Cavas et al., 2012; Chang et al., 2009; De Jong, 2007; Tsai \& Wen, 2015; White, 1997).

The significant preference of researchers to the categories of case studies and focus groups might also be related to their specific goals or the conditions under which they work. Researchers might be opting for case studies as they have access to studying particular situations, problems or phenomena over a certain period of time. Moreover, they might be opting for focus groups as they able to access particular contexts that they aim and can study holistically while they pay emphasis to a particular case or phenomenon in an explanatory process. Another reason might be that researchers are challenged when having to find large samples in order to carry other types of research-mostly of quantitative nature-even though they might still wish to do so. This might be because experimental studies, field surveys, or even secondary data analysis are also preferred, though not as much as cases studies and focus groups. In other words, it might be the case that researchers prefer to do these types of research. However, they may have to consider how to approach their data and subjects (Bhattacherjee, 2012; Cohen et al., 2007; Lin et al., 2019; Pring, 2000).

The fact that Action research or ethnography is not preferred probably means that few people, who are within a researchable context, express interest in carrying out research in the same context where they work. This shows lack of interest in interpretive design research on behalf of people who are actually involved in science teaching (Bhattacherjee, 2012; Cohen et al., 2007; Pring, 2000; Szyjka, 2012).

In comparison to the previous decades, it can be concluded that there are certain similarities in the trends of research in science education paradigms and types. There is an apparent insisting preference towards the qualitative paradigm. This might be due to the fact that researchers are concerned with the risk of generalizing a new trend or idea and therefore, they opt to reinforce the validity of an existing one by testing it in different and innovative contexts. Another reason might be their preference to ensure that research findings reflect and derive from firsthand experience in classrooms, the sessions, and the function of the educational system (Bhattacherjee, 2012; Cohen et al., 2007; Lin et al., 2019; Pring, 2000). Researchers maintain their aim to research issues relevant to instruction, curriculum, and curriculum interpretation as well as teaching practices. These findings are compatible to conclusions that were drawn from similar projects of the previous decade (Chang \& Cheng, 2010; De Jong, 2007; Lin et al., 2019; Szyjka, 2012). Certainly, quantitative research as well as mixed approach are still being used to a respected extent by the researchers. 
This probably means that there are research groups that have the opportunity or motivation to analyze data deriving from large number of samples or populations in an effort to evaluate topics, themes or issues at large scale-national or international level. To sum, it could be stated that the aims of researchers in science education and the conditions of their work have changed little in some respect (Bhattacherjee, 2012; Lin et al., 2019; Pring, 2000).

\section{CONCLUSIONS}

The scope of this bibliometric study was to identify the trends in preferences regarding the types of research in science education articles, published between 2011-2020. Itt aims to give insights into the trends and dynamics with regards to the particular topic (Cobo et al., 2011; Donthu et al., 2021; Zupic \& Čater, 2014). The selection of the research type that fits a particular study is a complicated process. Depending on many factors the researchers can opt what kind of study they prefer to implement. This can be quantitative study-experimental study, field survey, secondary data analysis, case research-or qualitative studycase study, focus group, action research, ethnography, or mixed study (Bhattacherjee, 2012; Pring, 2000; Walliman, 2011). The factors that influence the researchers might be relevant to the goals they have. Further, the factors may be relevant to the conditions under which they work. Therefore, by investigating these trends, it is possible to gain insights around these factors (Bhattacherjee, 2012; Cohen et al., 2007; Pring, 2000; Szyjka, 2012). The objective of this study lies exactly in that part.

Specifically, in the field of science education, similar research has concluded that in previous decades there was a preference to qualitative research even though there were a considerable number of quantitative studies as well (Cavas et al., 2012; Chang et al., 2009; De Jong, 2007; Lin et al., 2019; Tsai \& Wen, 2015; White, 1997).

The study was of quantitative nature (Bhattacherjee, 2012; Cohen et al., 2011; Pring, 2000; Walliman, 2011). The data are collected with the help of search engines. The present study focuses on search engines of science education journals. 2,071 articles from 10 journals-published between 2011-2020-were collected. They were classified based on the type of research adopted. The absolute and relevant frequencies were calculated (Cobo et al., 2011; Donthu et al., 2021; Zupic \& Čater, 2014). The findings showed that there is a preference toward qualitative studies, although there were enough quantitative or mixed studies as well. A reason for that can be that researchers aim to test already established research findings and theories in different contexts, instead of developing new theories. Another reason can be that they have easier access to these contexts, with the smaller samples, whereas gathering data from larger samples of population might be challenging. Generally, these findings agree with those of previous studies (Cavas et al., 2012; Chang et al., 2009; De Jong, 2007; Lin et al, 2019; Tsai \& Wen, 2015; White, 1997).

Before finishing, it is useful to stress limitations of the study and proposals for further research. In order to generalize these data, it would be useful to have more similar studies done, with a larger sample of articles and journals and a larger period. The sample of this study was the maximum possible, bearing in mind conditions and time restrictions. Moreover, it would be useful to triangulate these data with other data collection resources, such as interviews from the authors regarding the types they select (Cohen et al., 2011).
Funding: Author received no financial support for the research and/or authorship of this article.

Declaration of interest: Author declares no competing interest.

Data availability: Data generated or analyzed during this study are available from the author on request.

\section{REFERENCES}

Bhattacherjee, A. (2012). Social science research: Principles, methods and practices. Create Space Independent Publishing Platform. http://scholarcommons.usf.edu/oa_textbooks/3

Botes, W. (2021). The development and use of improvised scienceteaching models: A case of natural science pre-service teachers. International Journal of Learning, Teaching and Educational Research, 20(5), 18-37. https://doi.org/10.26803/ijlter.20.5.2

Callon, M., Courtial, J. P., Turner, W. A., \& Bauin, S. (1983). From translations to problematic networks: An introduction to co-word analysis. Social Science Information, 22(2), 191-235. https://doi.org/ 10.1177/053901883022002003

Cavas, B., Cavas, P., Ozdem, Y., Rannikmae, M., \& Ertepinar, H. (2012). Research trends in science education from the perspectives of Journal of Baltic Science Education: A content analysis from 2002 to 2011. Journal of Baltic Science Education, 11(1), 94-102.

Chang, Y.-H., Chang, C.-Y., \& Tseng, Y.-H. (2009). Trends of science education research: An automatic content analysis. Journal of Science Education and Technology, 19(4), 315-331. https://doi.org/10.1007/ s10956-009-9202-2

Cobo, M. J., López-Herrera, A. G., Herrera-Viedma, E., \& Herrera, F. (2011). Science mapping software tools: Review, analysis, and cooperative study among tools. Journal of the American Society for Information Science and Technology, 62(7), 1382-1402. https://doi.org/10.1002/asi.21525

Cohen L., Manion L., \& Morrison, K. (2011). Research methods in education. Routledge. https://doi.org/10.4324/9780203720967

De Jong, O. (2007). Trends in western science curricula and science education research: A bird's eye view. Journal of Baltic Science Education, 6(1), 15-22.

Donthu, N., Kumar, S., Mukherjee, D., Pandey, N., \& Lim, W. M. (2021). How to conduct a bibliometric analysis: An overview and guidelines. Journal of Business Research, 133, 285-329. https://doi.org/10.1016/j.jbusres.2021.04.070

Fraser, B. J., Tobin, K. G., \& McRobbie, C. J. (Eds). (2012). Second international handbook of science education. Springer. https://doi.org/10.1007/978-1-4020-9041-7

Kazempour, M., Amirshokoohi, A., \& Blamey, K. (2020). Putting theory to practice: Teaching the 5E learning cycle through immersive experiences for pre-service teachers. European Journal of Science and Mathematics Education, 8(1), 67-75. https://doi.org/10. 30935/scimath/9547

Lin, T.-J., Lin, T.-C., Potvin, P., \& Tsai, C.-C. (2018). Research trends in science education from 2013 to 2017: A systematic content analysis of publications in selected journals. International Journal of Science Education, 41(3), 367-387. https://doi.org/10.1080/ 09500693.2018.1550274 
McCollough, C., Wolff-Murphy, S., \& Blalock, G. (2019). Reforming science teacher education with cultural reflection and practice. International Journal of Learning, Teaching and Educational Research, 18(1), 31-49. https://doi.org/10.26803/ijlter.18.1.3

National Research Council. (2012). A framework for K-12 science education: Practices, crosscutting concepts, and core ideas. The National Academies Press. https://doi.org/10.17226/13165

NGSS. (2013). Next generation science standards, science and engineering practices in the NGSS. http://www.nextgenscience.org/nextgeneration-science-standards

OECD. (2000). Measuring student knowledge and skills: The PISA 2000 assessment of reading, mathematical and scientific literacy. OECD Publishing. https://doi.org/10.1787/9789264181564-en

OECD. (2006). Assessing scientific, reading and mathematical literacy: A framework for PISA 2006. OECD Publishing. https://doi.org/10. 1787/9789264026407-en

OECD. (2019). PISA 2018 results (volume II): Where all students can succeed, PISA. OECD Publishing. https://doi.org/10.1787/b5fd1b8f-en

Pring, R., (2000). Philosophy of educational research. Continuum. https://doi.org/10.1111/1467-8527.t01-1-00129

Salini, S. (2016). An introduction to bibliometrics. In T. Greenfield, \& S. Greener (Eds.), Research methods for postgraduates (pp. 130-143). John Wiley \& Sons, Ltd. https://doi.org/10.1002/9781118763025. ch14
Szyjka, S. (2012). Understanding research paradigms: Trends in science education research. Problems of Education in the 21st Century, 43, 110119. https://doi.org/10.33225/pec/12.43.110

Tobin, K., \& Kincheloe, J. L. (Eds). (2006). Doing educational research: A handbook. Sense Publishing. https://doi.org/10.1163/ 9789087901202

Tobin, K., \& Steinberg, S. R. (Eds). (2015). Doing educational research: A handbook. Sense Publishing. https://doi.org/10.1163/ 9789463000765

Tsai, C.-C., \& Wen, M. L. (2005). Research and trends in science education from 1998 to 2002: A content analysis of publication in selected journals. International Journal of Science Education, 27(1), 314. https://doi.org/10.1080/0950069042000243727

Viro, E., Lehtonen, D., Joutsenlahti, J., \& Tahvanainen, V. (2020). Teachers' perspectives on project-based learning in mathematics and science. European Journal of Science and Mathematics Education, 8(1), 12-31. https://doi.org/10.30935/scimath/9544

Walliman, N., (2011). Research methods: The basics. Routledge. https://doi.org/10.4324/9780203836071

White, R. (1997). Trends in research in science education. Research in Science Education, 27(2), 215-221. https://doi.org/10.1007/ BF02461317

Zupic, I., \& Čater, T. (2014). Bibliometric methods in management and organization. Organizational Research Methods, 18(3), 429-472. https://doi.org/10.1177/1094428114562629 